\title{
Postnatal development of rats exposed to fluoxetine or venlafaxine during the third week of pregnancy
}

V.A. da-Silva ${ }^{1}$, S.P. Altenburg ${ }^{1}$, L.R. M alheiros ${ }^{1}$, T.G. Thomaz ${ }^{1}$ and C.J. Lindsey ${ }^{2}$

\author{
${ }^{1}$ Núcleo de Ciências Comportamentais e do Desenvolvimento, \\ Departamento de Fisiologia, Instituto Biomédico, U niversidade Federal Fluminense, \\ Niterói, RJ, Brasil \\ 2Departamento de Biofísica, Universidade Federal de São Paulo, São Paulo, SP, Brasil
}

\author{
Correspondence \\ V.A. da-Silva \\ Núcleo de Ciências \\ Comportamentais e do \\ Desenvolvimento, Departamento \\ de Fisiologia, UFF \\ Rua Hernani Melo, 101 \\ 24210-130 Niterói, RJ \\ Brasil \\ Fax: +55-21-620-5266 \\ E-mail: mflvilm@ vm.uff.br
}

Publication supported by FAPESP.

Received Abril 9, 1998

Accepted O ctober 22, 1998

\section{Abstract}

The aim of the present study was to compare the toxic effects of fluoxetine (F) (8 and $16 \mathrm{mg} / \mathrm{kg}$ ) and venlafaxine (V) (40 and $80 \mathrm{mg} / \mathrm{kg})$ administered during the third week of pregnancy on early development of rats. Both antidepressants were administered by gavage on pregnancy days 15 to 20 to groups of 10 to 12 animals each. Duration of gestation, food and water consumption, number of live pups and birth weight were recorded. Litters were culled to six pups at birth (day 1) and followed for growth until weaning (day 25). On day 60, a male and a female from each litter were injected with the 5-HT 1 agonist, 5 -methoxy-N,N-dimethyltryptamine $(6 \mathrm{mg} / \mathrm{kg}$, ip $)$ and the serotonergic syndrome was graded. Fluoxetine but not venlafaxine reduced the duration of pregnancy when compared to the control $(\mathrm{C})$ group $(\mathrm{F}=$ 21.1 days and $\mathrm{C}=21.6$ days, mean, $\mathrm{P}<0.02$; maximum $=22$ days and minimum $=21$ days in both groups). The highest doses of both fluoxetine, $16 \mathrm{mg} / \mathrm{kg}$ (F16), and venlafaxine, $80 \mathrm{mg} / \mathrm{kg}$ (V80), reduced the food intake of pregnant rats, resulting in different rates of body weight gain during treatment (from pregnancy day 15 to day 20): F16 $=29.0 \mathrm{~g}, \mathrm{~V} 80=28.7 \mathrm{~g} v s \mathrm{C}=39.5 \mathrm{~g}$ (median). Birth weight was influenced by treatment and sex $(\mathrm{P}<0.05$; two-way ANOVA). Both doses of fluoxetine or venlafaxine reduced the body weight of litters; however, the body weight of litters from treated dams was equal to the weight of control litters by the time of weaning. At weaning there was no significant difference in weight between sexes. There was no difference among groups in number of live pups at birth, stillbirths, mortality during the lactation period or in the manifestation of serotonergic syndrome in adult rats. The occurrence of low birth weight among pups born to dams which did not show reduced food ingestion or reduction of body weight gain during treatment with lower doses of fluoxetine or venlafaxine suggests that these drugs may have a deleterious effect on prenatal development when administered during pregnancy. In addition, fluoxetine slightly but significantly affected the duration of pregnancy (about half a day), an effect not observed in the venlafaxine-treated groups.
Key words - Development

- Fluoxetine

- Venlafaxine

- Rats 
The puerperal period has long been recognized as an increased risk factor for behavioral disorders and mental illness. Epidemiological studies have shown a dramatic increase in the rates of first new psychiatric episodes for women during the 3-month period following childbirth. At least $80 \%$ of these psychiatric episodes represent mood disorders (1). On the other hand, vulnerability of pregnancy to mood disorders was recognized only recently $(2,3)$. Non-psychotic depressive illness affects $38 \%$ of women in the third trimester of pregnancy (2). Moreover, some anxiety disorders such as panic disorders may worsen during pregnancy, requiring pharmacological treatment (4). Maternal depression, if not treated, can lead to chronic or recurrent mood disorder in the mother (5) and disturbances in behavior and cognitive development in the infant (6). Pharmacological therapy of depression or anxiety during pregnancy creates the clinical dilemma of exposing the unborn brain to psychoactive drugs. On the other hand, because a large proportion of pregnancies are unplanned, fetal exposure may occur when a woman of childbearing age is using an antidepressive medication. Fluoxetine was the first of several highly selective inhibitors of neuronal serotonin uptake that were shown to be effective in the treatment of clinical depression (7). Since then, fluoxetine and the new group of drugs known as specific reuptake inhibitors have been widely used for a variety of medical conditions. Other nonselective serotonin reuptake inhibitors such as venlafaxine are also used to treat depressive disorders. Notwithstanding the widespread use and increasing potential application of serotonin reuptake inhibitors during pregnancy or during breast feeding, little is known about their potential developmental toxicology. A few studies on the effects of fluoxetine on development were published. The study by Nulman et al. (8) indicates that it is not teratogenic and does not affect the neurodevelopment of children exposed during the first trimester of gestation. In contrast to these results, in vitro developmental toxicity studies have demonstrated that fluoxetine and sertraline, another serotonin reuptake inhibitor, disrupt normal craniofacial morphogenesis in mouse embryos, presumably by inhibiting serotonin uptake into differentiating craniofacial epithelia (9). Other findings from in vivo developmental assessments are contradictory. Some reports do not show functional or behavioral deficits in the offspring (10) but others have reported behavioral alterations in the adult progeny as a result of prenatal exposure (11). To our knowledge, prospective controlled studies on the developmental toxicology of venlafaxine have not been performed. The latter drug purportedly may be effective in some cases of refractory depression (12), and thus its possible prescription during pregnancy or during the puerperal period should be considered.

The aim of the present study was to compare the toxic effects of fluoxetine and venlafaxine on the development of rat offspring exposed during pregnancy. Comparisons of the toxicologic profiles of these drugs in the same study may provide useful information for clinical situations where an option for pharmacological therapy is required. In order to start this toxicologic comparison of the two drugs during the developmental process, we selected the third week of pregnancy as the time of drug exposure. It is known from the available literature (13) that the peak of cell differentiation for serotoninergic neurons occurs on gestational days $15-$ 16 and by gestational day 19 the distribution of serotonin neurons resembles that found in the adult. Therefore, these drugs, both inhibitors of serotonin reuptake, might interfere with the developing serotoninergic system at this critical time. Experimental studies on the effects of antidepressants during the last part of pregnancy are also important if we consider that maternal depression may occur in $38 \%$ of women during the third 
trimester of pregnancy (2). Thus, questions about the interference of antidepressants with labor and their potential for inducing premature births and presenting fetotoxicity must be raised.

Female Wistar rats from our breeding colony weighing approximately $200 \mathrm{~g}$ were mated overnight to males of the same stock, in a harem system. Vaginal smears were collected and the presence of sperm was used to determine gestational day 0 . Ten to 12 pregnant dams per group were exposed to either 8 or $16 \mathrm{mg} / \mathrm{kg}$ of fluoxetine (F8 or F16) or 40 or $80 \mathrm{mg} / \mathrm{kg}$ of venlafaxine (V40 or V80) administered intragastrically by gavage from gestational day 15 to 20 . A control group (C) was gavaged with the vehicle (water). Food and water consumption during treatment was recorded. Doses of fluoxetine were selected from a previous experimental study on the embryotoxicity of fluoxetine carried out on rats (14). In this study, the developmental no observed adverse effect level (NOAEL) was $12.5 \mathrm{mg} / \mathrm{kg}$. We chose 8 and $16 \mathrm{mg} / \mathrm{kg}$ dose levels which were lower and slightly higher than the NOAEL for embryotoxicity in order to look for the potential functional toxicity of lower doses and in order to obtain information for the design of future studies on behavioral teratology. Functional and behavioral toxicity is assumed to occur at dose levels lower than those involved in embryotoxicity. Less information was available on the developmental effects of venlafaxine. Therefore, we based our dose selection on the information from the manufacturer referring to experimental studies in which the only toxic effect reported was delayed rat development at the dose of $80 \mathrm{mg} / \mathrm{kg}$. In our study we selected 40 and $80 \mathrm{mg} / \mathrm{kg}$. Thus, we used a weight ratio of 5:1 for venlafaxine and fluoxetine in the present study. It should be pointed out that this same proportion of doses is reported in clinical practice (maximum dose levels of $80 \mathrm{mg} /$ day and $275 \mathrm{mg}$ /day for fluoxetine and venlafaxine, respectively).
From day 21 of pregnancy onwards, cages were inspected twice daily to detect births. Gestation length, number of live pups at birth and birth weight were recorded. Litters were culled to six pups at birth (day 1). Maternal behavior was evaluated daily at 9:00 a.m. by recording whether the mother was in the nest. Weaning was performed on day 25 and pups were weighed and separated by gender. On day 60 , one male and one female from each litter were injected with the $5 \mathrm{HT}_{1}$ agonist, 5-methoxy-N,N-dimethyltryptamine $(6 \mathrm{mg} / \mathrm{kg}$, ip $)$ and behavioral responses (forepaw treading and hind limb abduction) were recorded in 5 independent evaluations along $16 \mathrm{~min}$ and graded according to intensity (15). The ranked intensity scale was $0=$ absent, $1=$ present, $2=$ moderate and $3=$ intense. Observers were blind to animal treatment.

Fluoxetine but not venlafaxine significantly shortened pregnancy (Table 1). The effect was mild (around half a day) but consistent at the two dose levels. The effect was statistically significant when groups F8 and F16 were combined and compared to the control group. Venlafaxine had no effect even when data for the two dose levels were combined. Both fluoxetine $16 \mathrm{mg} / \mathrm{kg}$ and venlafaxine $80 \mathrm{mg} / \mathrm{kg}$ decreased food consumption and weight gain of the dams during treatment, whereas the lower doses of each compound did not affect food intake or weight gain of dams (Table 1). Birth weight was affected by treatment and by sex (Figure 1). A decrease in body weight at birth was detected in all the litters of dams treated with the low (F8, V40) or high doses (F16, F80) of fluoxetine or venlafaxine as compared to the control group. At birth females had lower body weight than males. The effect on pregnancy duration may be linked to the intense and selective serotonergic action of fluoxetine since venlafaxine, a nonselective reuptake inhibitor (12), did not affect pregnancy duration. The effect of treatment of dams with fluoxetine or venlafaxine on prog- 
eny body weight at birth was apparent for all treated groups, even those which received the lower doses of the compounds. Venlafaxine or fluoxetine 8 or $40 \mathrm{mg} / \mathrm{kg}$, respec- tively, did not decrease food consumption or body weight in dams although their litters were born with lower body weight than controls (Table 1 and Figure 1), indicating that

Table 1 - Effect of fluoxetine or venlafaxine administered to pregnant rats from day 15 to day 20 of gestation.

Fluoxetine (8 (F8) or $16(\mathrm{~F} 16) \mathrm{mg} / \mathrm{kg}$ ) or venlafaxine (40 (V40) or $80(\mathrm{~V} 80) \mathrm{mg} / \mathrm{kg}$ ) was administered by gavage daily from gestational day 15 to 20 . The control (C) group was treated with water. Data on food consumption represents total consumption from day 15 to 20 . Weight gain is the difference in body weight between day 20 and 15. Groups were compared by the Kruskal-Wallis test followed by the Mann-Whitney U-test. Values are reported as the mean and maximum and minimum values (between parentheses). Statistical analysis: $a: \neq F 8$; $\mathrm{b}: \neq \mathrm{V} 40 ; \mathrm{c}: \neq \mathrm{C} ; \mathrm{d}: \mathrm{F}<\mathrm{C} ; \mathrm{P}=0.02$.

\begin{tabular}{cccccc}
\hline & $\mathrm{C}(\mathrm{N}=10)$ & $\mathrm{F} 8(\mathrm{~N}=11)$ & $\mathrm{F} 16(\mathrm{~N}=12)$ & $\mathrm{V} 40(\mathrm{~N}=11)$ & $\mathrm{V} 80(\mathrm{~N}=11)$ \\
\hline $\begin{array}{c}\text { Food consumption }(\mathrm{g}) \\
\text { (day 15 to 20) }\end{array}$ & 133.5 & 126.0 & $108.7^{\mathrm{a}, \mathrm{c}}$ & 130.6 & $114.7^{\mathrm{b}, \mathrm{c}}$ \\
Weight gain (g) & $39.3-145.3)$ & $(109.3-141.3)$ & $(90.9-131.3)$ & $(108.1-169.9)$ & $(79.1-133.8)$ \\
$\quad$ (day 15 to 20) & $(23.6-49.6)$ & $(25.6-52.9)$ & $(14.8-43.7)$ & $(15.0-51.1)$ & $(-15.9-48.3)$ \\
Duration of gestation & 21.6 & $21.1^{\mathrm{d}}$ & $21.2^{\mathrm{d}}$ & 21.4 & 21.6 \\
$\quad$ (days) & $(21-22)$ & $(21-22)$ & $(21-22)$ & $(21-22)$ & $(21-24)$
\end{tabular}
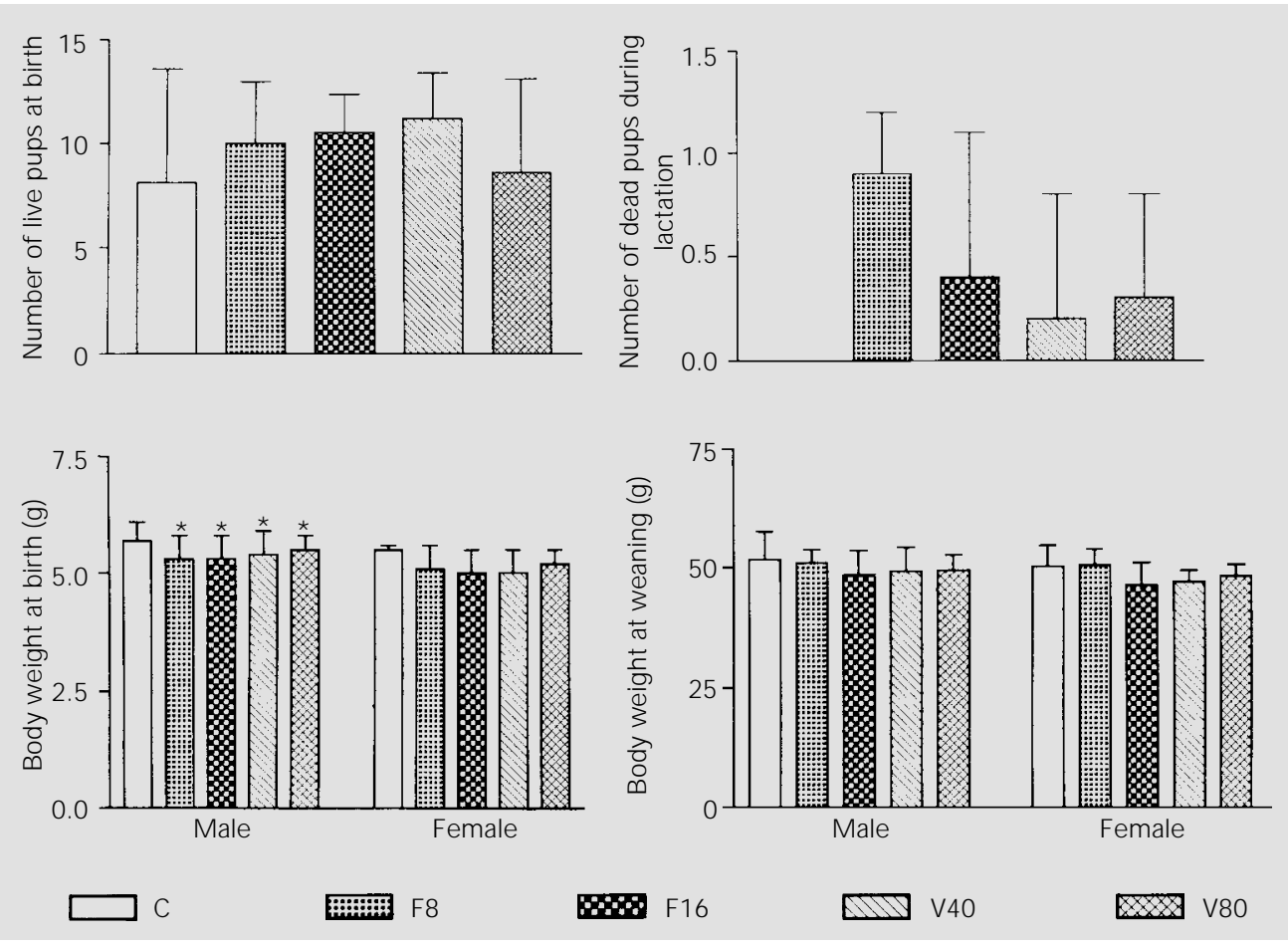

Figure 1 - Effects on offspring of fluoxetine or venlafaxine administered to pregnant rats. Fluoxetine (8 (F8) or 16 (F16) $\mathrm{mg} / \mathrm{kg}$ ) or venlafaxine ( 40 (V40) or 80 (V80) $\mathrm{mg} / \mathrm{kg}$ ) was administered by gavage daily from gestational day 15 to 20. The control (C) group was treated with water. Litters were used as the unit for statistical analysis. Groups were compared by two-way (body weight) or one-way (live pups at birth) ANOVA followed by the Student t-test or the Kruskal-Wallis test and by the Mann-Whitney U-test (mortality during lactation). Values are reported as the mean \pm SD. $* P<0.05$ compared to controls and to female rats of the same group $(\mathrm{P}<0.05$ for treatment and sex: two-way ANOVA). 
the effect on offspring body weight is not an indirect effect caused by reduced maternal food intake. Thus, the possibility that these compounds had a direct fetotoxic effect on unborn pups must be considered. By weaning time, at 25 days of age, body weight was the same in all treated and control groups. Recovery of body weight was confirmed in adulthood (110 days), when pharmacological testing was performed (male: $\mathrm{C}=322.6 \pm$ $4.6 \mathrm{~g}, \mathrm{~F} 8=322.1 \pm 5.7 \mathrm{~g}, \mathrm{~F} 16=328.7 \pm 25.7$ $\mathrm{g}, \mathrm{V} 40=326.2 \pm 6.9 \mathrm{~g}, \mathrm{~V} 80=327 \pm 19.5 \mathrm{~g}$ and female: $\mathrm{C}=209.3 \pm 0.8 \mathrm{~g}, \mathrm{~F} 8=216.5 \pm$ $4.2 \mathrm{~g}, \mathrm{~F} 16=208.2 \pm 3.9 \mathrm{~g}, \mathrm{~V} 40=199.4 \pm 2.1$ $\mathrm{g}, \mathrm{V} 80=208.8 \pm 5.7 \mathrm{~g}$ ). The recovery of body weight to control levels during lactation is common to other models such as in utero malnutrition which show low body weight at birth (16). Females of all groups had lower body weight than males of the same group. By the time of weaning, body weight of females was the same as that of males in all groups.

The number of live pups at birth and mortality during lactation were the same in control and treated groups. Maternal behavior, as measured, apparently was not affected by treatment with either fluoxetine or venlafaxine. Adult animals tested for behavioral responses to 5-methoxy-N,N-dimethyltryptamine showed the same grade of responses whether from litters born to control or treated dams. Behavioral scores derived from the sum of 5 grades given in independent evaluations along 16 min were (median): $\mathrm{C}=9 ; \mathrm{F} 8=8.5 ; \mathrm{F} 16=9 ; \mathrm{V} 40=9.5$ and $\mathrm{V} 80$ $=9($ Kruskal-Wallis, $\mathrm{P}>0.05)$. Although these behavioral data suggest that the serotoninergic system was not affected under the experimental conditions studied, additional studies on serotonin brain levels or turnover are needed before any definitive conclusion can be reached.

The demonstration of a reduction in gestation length caused by fluoxetine and the reduction of birth weight caused by both fluoxetine and venlafaxine are indications of the potential toxic effects of these compounds on the progeny when administered during pregnancy. Extrapolation to a clinical situation would call for careful considerations regarding dose relationships and interspecies differences. However, any indication of prenatal toxicity in animals for medications of potential use during pregnancy should be examined carefully.

\section{Acknowledgments}

We thank Wyeth-Whitehal Laboratories (Brazil) and Eli Lilly (Brazil) for their kind gift of venlafaxine and fluoxetine $\mathrm{HCl}$, respectively. We are also grateful to FAPERJ for providing financial support to present part of this work at the XIII International Congress of Pharmacology, Germany, July, 1998.

\section{References}

1. Kendell RE, Chalmers J C \& Platz C (1987). Epidemiology of puerperal psychoses. British J ournal of Psychiatry, 150: 662673.

2. Da-Silva VA, Moraes-Santos AR, Carvalho MS, Martins MLP \& Teixeira NA (1998). Prenatal and postnatal depression in low income Brazilian women. Brazilian J ournal of Medical and Biological Research, 31: 799-804.

3. Kitamura T, Shima S, Sugawara M \& Toda MA (1991). Stress and puerperal psychosis. British J ournal of Psychiatry, 158: 290291.
4. Cohen LS, Sichel DA, Dimmock VA \& Rosenbaum VF (1994). Impact of pregnancy on panic disorder: a case series. J ournal of Clinical Psychiatry, 55: 289-292.

5. Kumar R \& Robson KM (1984). A prospective study of emotional disorders in childbearing women. British J ournal of Psychiatry, 144: 35-47.

6. Cogill S, Caplan H, Alexandra H, Robson $\mathrm{K}$ \& Kumar R (1986). Impact of postnatal depression on the developing child. British Medical J ournal, 292: 1165-1167.

7. Sommi RW, Crismon ML \& Bowden CL (1987). Fluoxetine: a serotonin-specific, second generation antidepressant. Pharmacotherapy, 7: 1-15.

8. Nulman J, Rovet J Stewart D, Kulin NA \& Koren G (1996). Neurodevelopment of children exposed to fluoxetine in utero: a prospective longitudinal study. Clinical Pharmacology and Therapeutics, 59: 159 (Abstract).

9. Shuey DL, Sadler TW \& Lauder J M (1992). Serotonin as a regulator of craniofacial morphogenesis site specific malformations following exposure to serotonin uptake inhibitors. Teratology, 46: 367-378.

10. Vorhees CV, Acuff-Smith KD, Schilling 
MA, Fisher JE \& Buelke-Sam J (1992). Evaluation of the behavioral teratogenic potential of fluoxetine in rats. Teratology, 45: 526A-527A.

11. Livezey GT, Styilk K, Olson K \& Smith CV (1996). Alterations in the behavior of adult rat progeny after prenatal exposure to fluoxetine. Society for Neuroscience Abstracts, 22: 1967.

12. Post RM (1995). Mood disorders: somatic treatment. In: Kaplan HI \& Sadock BJ (Editors), Comprehensive Textbook of Psy- chiatry. Williams \& Wilkins, Baltimore.

13. Druse MJ (1992). Effects of in utero ethanol exposure on the development of neurotransmitter systems. In: Miller MW (Editor), Development of the Central Nervous System: Effects of Alcohol and Opiates. Wiley-Liss, New York.

14. Byrd RA \& Markham J K (1994). Developmental toxicology studies of fluoxetine hydrochloride administered orally to rats and rabbits. Fundamental and Applied Toxicology, 22: 511-518.
15. Fulginiti S, Vigliecca NS \& Minetti SA (1992). Acute ethanol intoxication during pregnancy: postnatal effects on the behavioral response to serotonin agents. Alcohol, 9: 523-527.

16. Malheiros LR (1996). Desenvolvimento Neurocomportamental de Ratos Desnutridos e Expostos ao Etanol in Utero. Universidade Federal Fluminense, Rio de J aneiro, Brasil. 